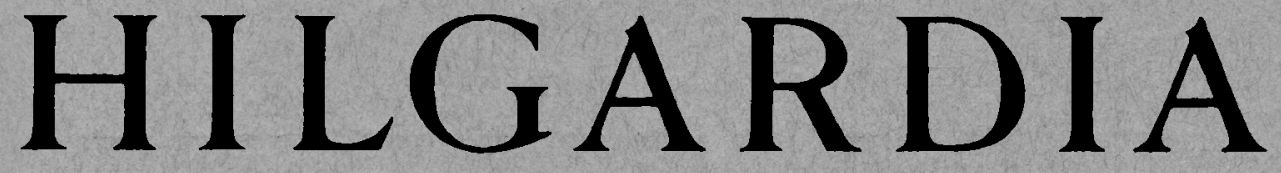

A Journal of Agricultural Science Published by the California Agricultural Experiment Station

\title{
FIELD TESTING OF GRAPE MATURITY
}

M. A. AMERINE and E. B. ROESSLER 
Since harvesting grapes at the proper stage of maturity is essential to quality-whether the grapes are intended for winery, table, or raisin use - an accurate means of estimating maturity in the field is necessary. Experiments were designed to measure the reliability of three field sampling methods-individual berry, cluster, and whole vine-in order to provide a more rational basis for grower practice. The varieties tested were Semillon and Carignane in regions II, IV, and V, Thompson Seedless in regions IV and V, and Flame Tokay in region IV. The degree Balling, Abbé refractometer reading, per cent reducing sugar, per cent total acidity, and $\mathrm{pH}$ were determined on all samples. According to these analyses, the three methods compare very favorably. It is suggested, however, that berry sampling, since it is the simplest and most rapid of the three methods, may be the most practical. 


\section{$\begin{array}{llllllll}H & \text { I } & \text { L } & G & \text { A } & \text { R } & \text { D I } & \text { A }\end{array}$}

A Journal of Agricultural Science Published by

the California Agricultural Experiment Station

\begin{tabular}{lll}
\hline Vol. 28 & NOVEMBER, 1958 & No. 4 \\
\hline
\end{tabular}

\section{FIELD TESTING OF GRAPE MATURITY ${ }^{1}$}

\section{A. AMERINE and E. B. ROESSLER}

\section{INTRODUCTION}

ENoLogists are agreed that harvesting wine grapes at the proper stage of maturity is of critical importance to the quality of the wine. Table grapes, particularly early in the season, also vary in quality with maturity (see, for example, Winkler, 1932). For maximum quality, raisin grapes likewise, according to Jacob (1942), should not be harvested before a certain degree of ripeness. However, to harvest at the ideal composition-whether the grapes are intended for winery, table, or raisin use-it is necessary to determine the true composition of the fruit in the field in order to establish the date when the proper stage of maturity is reached. To measure the composition of the fruit in the field involves making field tests of the grapes on the vine during their maturation. This preliminary paper deals with the relative reliability of various methods of field testing for the purpose of determining maturity for harvesting.

For various reasons it is not easy to establish the best method of measuring the maturity of grapes in the field. Naturally, if all the fruit ripened evenly and at the same time, field sampling would present no problem, since a large or small sample would then be satisfactory. However, the grapes on the vine do not ripen at the same rate. Each berry and cluster differs in its rate of ripening. Therefore, each cluster, vine, or vineyard may differ in ripening from every other. The position of the fruit on the vine; the location of the vine in the vineyard with respect to exposure, soil moisture, humidity, and temperature; the amount of crop ; and soil differences-these are some of the other variables that must be considered.

The variability in composition of grapes within a single field is well known. This is only another aspect of the universal heterogeneity which we find in nature. When variability is small, no very extensive experiment is required to determine as closely as desired the true mean of a field. If, on the other hand, as with grapes, the variability is larger, we must, as Fisher (1950) has pointed out, randomize and replicate our samples to obtain an estimate

${ }^{1}$ Submitted for publication May 27, 1957.

${ }^{2} \mathrm{Mr}$. Amerine is Professor of Enology and Enologist in the Experiment Station, Davis; Mr. Roessler is Professor of Mathematics and Statistician in the Experiment Station, Davis. 
statement of the accuracy of our results. Berg and Marsh (1954) in a study of sampling from a load of grapes also noted the great variability of commercially harvested fruit. Even when fourteen 5-pound samples were taken from loads of 180 to 220 boxes (about 40 pounds each), the average deviation amounted to $0.57^{\circ}$ Balling, and the maximum possible deviation was $1.4^{\circ}$ Balling.

While maturation in this study has been followed by determining sugar, total soluble solids, acidity, and $\mathrm{pH}$, Amerine (1956) lists a number of other measures of maturity which may be used. Some data on weight per vine, per cluster, and per berry during maturation are also included in this study.

These experiments were designed to measure the reliability of various methods of sampling grapes in the field in order to give a more rational basis for grower practice. In sampling grapes, several practical limitations present themselves. One is that vines in many vineyards are supported on wires in the rows, and it is difficult to move across rows for sampling. Sampling in the row is thus more convenient than between the rows. However, irrigation is usually down the rows, and the growth and ripening may vary markedly from one end of the row to the other depending on the amount of water used and the climatic region. While we have attempted to compensate for this factor by using in most cases blocks from the middle of the field, the effect of this variable might well be measured.

In addition to the problem of sampling which is implicit in the study of Berg and Marsh (1954), several other recent studies of field sampling may be noted. Andre et al. (1951) used 20 randomly selected clusters and reported, without presenting statistical data, that their means offered a fair indication of maturity. They avoided clusters from vines at the end of rows; at regular intervals (interval not stated) they selected at random clusters from all sides of the vines (the distance was apparently dependent on the size of the vineyard sampled); they did not harvest abnormal clusters (a difficult procedure if the selection of clusters was random); and they harvested not more than about 5 pounds, although at least 20 clusters were used.

Benvegnin and Capt (1955) compared berry and cluster samplings and preferred the former. The number of samples was admittedly small. Huglin (1955) reported 50 to 100 berries to give mean values similar to those for 50 to 100 clusters. No statistical data were given, but their frequency curve (fig. 1) suggests that the berry and cluster samples for refractometer readings were indeed similar. Flanzy (1955) selected "typical" clusters. No data were given as to the validity of the procedure, and the selection is admittedly "difficult."

\section{SAMPLING PROCEDURES}

Three basic systems of sampling were studied in 1956: (1) single berries were taken from individual clusters on a large number of vines; (2) single clusters were taken from a smaller number of vines; and (3) all the fruit was collected from a few vines. In commercial practice the second and third 
methods are normally used. The single berry procedure was first studied by Benvegnin and Capt (1955) and Huglin (1955) with good results.

It was originally believed that simple sampling procedures were possible. At the first harvesting of the Delano, Lindsay, and Davis samples, berry and cluster samples were taken without regard to their position on the vine. Thereafter, however, a definite schedule was followed. The first berry or cluster was taken from one side of the vine, the next from the center, and

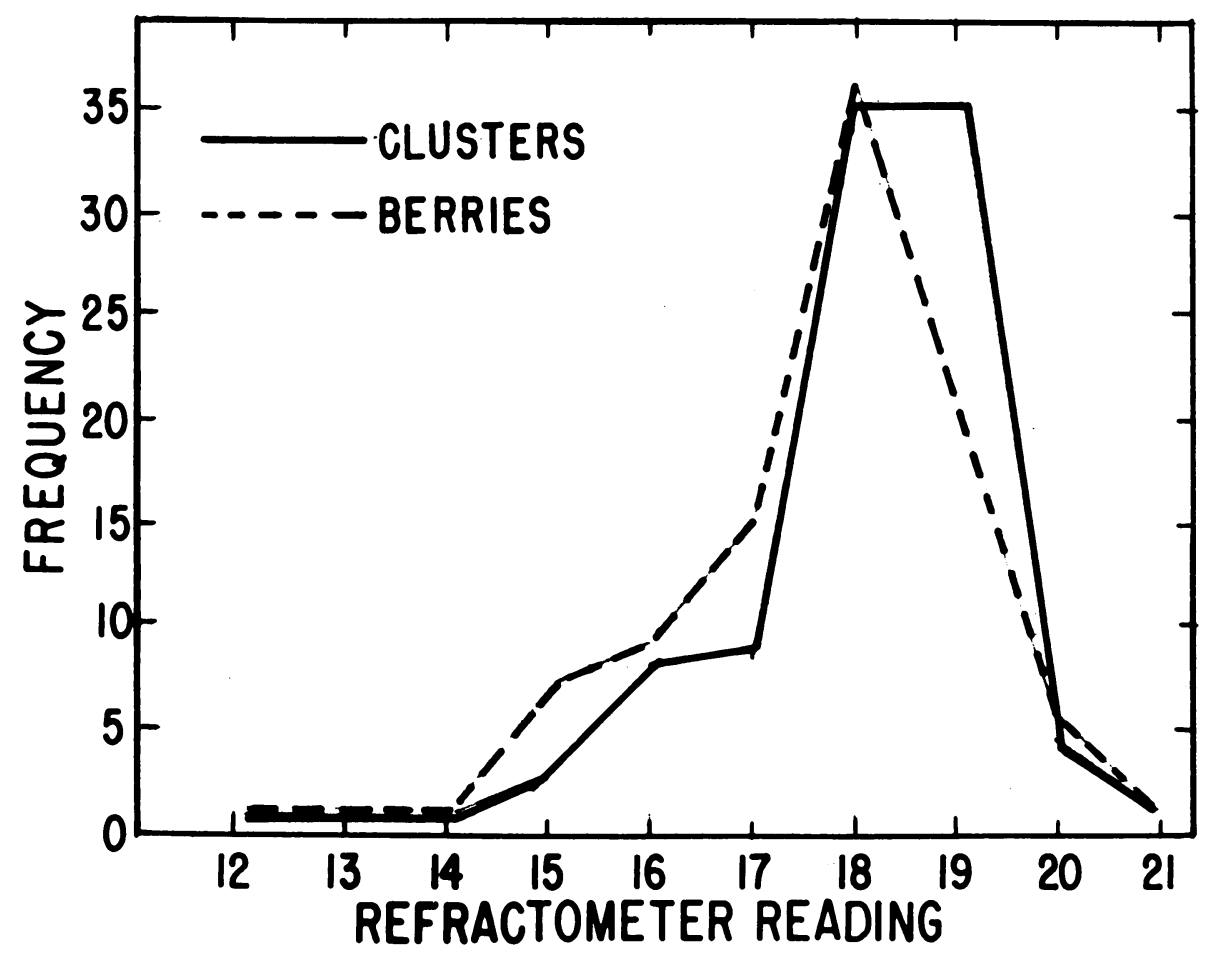

Fig. 1. Frequency distribution of refractometer readings of 100 berries compared with those of 100 clusters (after Huglin, 1955).

the next from the opposite side. The berry samples were taken in groups of nine: three from low, middle, and high on the cluster, and from three clusters on the left, right, and middle of the vine. In addition, rows were sampled from opposite sides. Without making the sampling system unduly cumbersome and time-consuming, this is about the limit of selection that can be applied practically.

The varieties and regions sampled were as follows:

Delano. At Delano with Semillon and Carignane, 1,000 vines (50 vines in 20 rows) were used as a group. The Semillon was cane-pruned on wires, and the Carignane was cordon-pruned. Both were about 20 years old.

For the berry samples, a single berry was taken from each Carignane vine and two from each Semillon vine. The 100 (or 200) berries collected from the 100 vines in rows 1 and 2 were crushed together as a lot. So were 
the berries from rows 3 and 4, etc., making ten 100- or 200-berry sample lots.

For the clusters, one cluster was taken from each of 10 vines (from vines $1,11,21,31$, and 41 in row 1 , and from vines $2,12,22,32$, and 42 in row 2 ). These 10 clusters were considered as a single lot and crushed together. Another 10 clusters were taken from vines $3,13,23,33$, and 43 in row 3 and from vines $4,14,24,34$, and 44 in row 4 and crushed together as a second lot. In all, 10 cluster lots were sampled.

For the whole-vine samples, the following vines were picked at the first harvest: row 1 , vine 4 ; row 4 , vine 31 ; row 5 , vine 16 ; row 7 , vine 41 ; row 10 , vine 7 ; row 11 , vine 28 ; row 13 , vine 46 ; row 15 , vine 11 ; row 18 , vine 36 ; and row 19, vine 20 . For the second harvesting, the preceding vine in the row was sampled.

Where a vine to be sampled was missing or of another variety, samples (berry, cluster, or vine) were taken from the next vine. In the Semillon block there were about 10 such cases. The Carignane block, however, was very uniform, and only three or four misses or odd vines occurred.

In normal practice 100 vines is assumed to be as many as can be sampled for berries, and 10 for clusters or vines. One reason for this is the time involved in sampling. Another is the loss of fruit from a small plot. And, practically, with many varieties, 10 clusters is often as many as can be easily carried in a large bag, though with some varieties more could be carried.

Lindsay. The Thompson Seedless block at Lindsay was in a 50-acre vineyard. The vines were old, about 30 to 40 years. The block again consisted of 1,000 vines, this time in the middle of the field. There were about 24 misses for which an adjacent vine was sampled. Because the berries were small, two berries per vine were collected, making 200 berries in each sample.

Livingston. Thompson Seedless was also sampled from a block in a large vineyard near Livingston. The vines were about 20 years old. This block consisted of 1,000 vines, 20 rows of 50 vines each, and 10 berry lots, 10 cluster lots, and 10 vine lots were harvested, as at Delano and Lindsay. One difficulty in harvesting the vine lots was that the vines were only 6 feet apart in the row and the canes overlapped, making it difficult to be sure which vine was being sampled.

Davis. At Davis no large blocks were available, so the sampling procedure was modified. The Semillon block (head-pruned) consisted of 88 vines, 22 vines each in four rows. The vines were 7 years old and were very uniform; there were no missing or odd vines. A half-row constituted a sampling group.

For the berry samples, 10 berries were collected from each vine in row 1 , vines 1 to 11, making a lot of 110 berries, and another lot was collected from vines 12 to 22 . This was repeated in the other rows, making 8 lots of berry samples. Two further lots of berries were collected over the whole block; for these a single berry was taken from each of the 88 vines.

For the cluster samples, two clusters were taken from each vine in row 1 , vines 1 to 11, and crushed together as a single lot. Then two clusters were taken from vines 12 to 22 as another lot, and so on for the other rows, making 8 lots of clusters. Eight whole-vine samples were collected as fol- 
lows: row 1 , vines 4 and 20 ; row 2 , vines 9 and 14; row 3 , vines 6 and 18 ; and row 4 , vines 10 and 22 .

At the second harvest there were only 80 vines remaining in the block. The berry and cluster samples were taken as before (but from 10 vines in each sampling group-100 berries and 10 clusters per lot), and then 8 vines (one in each sampling group) were picked clean. In each row the vine preceding that previously harvested was sampled. The two all-vine berry samples contained only 80 berries each.

At the third picking only 72 vines remained, 9 in each block. There were thus only 90 berries and 9 clusters per lot. At this harvesting two vines from each sampling group (16 in all) were picked clean. The all-vine berry samples contained only 72 berries. Finally, at a fourth picking, the remaining 56 vines were harvested, and the fruit from each was crushed and analyzed separately.

The Carignane block at Davis (6 years old and head-pruned) consisted of 10 rows of 22 vines per row, or 220 vines in all. The vines were uniform in age and size, and there were no misses. The berry samples consisted of 5 berries per vine, or 110 per lot. Each row was sampled separately, so there were 10 lots. The clusters were selected from alternate odd vines in the oddnumbered rows and from alternate even-numbered vines in the even rows, so these lots consisted of 11 clusters each. One vine from each row was then picked (vines $6,19,10,7,15,5,18,14,20$, and 2 in rows 1 to 10 respectively).

For the second picking the same schedule was maintained, but this time berry samples contained only 105 berries and the cluster samples 10 clusters. Where necessary, berry and cluster samples were taken from vines adjacent to those harvested at the first picking. The vines sampled were those adjacent to the ones harvested at the first picking. At the third harvesting only rows 4 and 5 were sampled. Five berries were taken from each vine in these rows, and then all the vines in these rows were harvested separately. Since there were then only 20 vines per row, the berry samples consisted of 100 berries, and there were 40 vine lots in all. Finally, a fourth picking was made, with all the remaining 56 vines being harvested separately.

The Flame Tokay block (6 years old and cordon-trained) was the same as the Carignane block in size and arrangement, and the same picking schedule was followed for the first and second pickings. However, in the first picking some clusters in row 7 were bagged for another experiment, so no samples were taken from this row. Row 8 was sampled twice, once according to the picking schedule for row 7 and once as if it were row 8 . Row 7 was sampled normally at the second picking.

Several other sampling experiments were made at Davis to determine the source of the variability. These included analyses of individual clusters and of single berries from a single cluster. These results will be analyzed later.

Rutherford. The Semillon block at Rutherford consisted of approximately 1,000 head-pruned vines, 50 vines each in 20 rows. The vines were not at all uniform, since they were at least 40 years old and had been regrafted about 25 years previously; misses (for which adjacent vines were sampled) amounted to about 10 per cent. As at Delano, at the first picking a single 
berry was taken from each vine in paired rows, so that there were 100 berries per lot. The pattern of vine sampling was the same as in the Delano experiments. At the second harvesting rows 1 to 10 were sampled individually (instead of 5 lots there were then 10 lots each of berries from these rows). Two berries were harvested, so that there were 100 berries in these lots.

TABLE 1

COMPOSITION OF MUSCAT OF ALEXANDRIA GRAPES CRUSHED BY VARIOUS METHODS

\begin{tabular}{|c|c|c|c|c|c|c|}
\hline Method & $\begin{array}{l}\text { Weight } \\
\text { of fruit }\end{array}$ & Balling & Abbé & $\begin{array}{l}\text { Reducing } \\
\text { sugar }\end{array}$ & $\begin{array}{l}\text { Total } \\
\text { acid }\end{array}$ & $\mathrm{pH}$ \\
\hline & lbs. & degrees & degrees & $\%$ & $\%$ tartaric & \\
\hline \multirow[t]{2}{*}{ Waring Blendor. . } & 5 & 27.7 & 27.9 & 27.2 & 0.55 & 4.03 \\
\hline & 5 & 27.9 & 28.0 & 27.6 & 0.56 & 4.05 \\
\hline \multirow[t]{2}{*}{ Screw crusher.. } & 25 & 27.2 & 27.2 & 25.9 & 0.48 & 3.90 \\
\hline & 25 & 27.4 & 27.3 & 27.0 & 0.48 & 3.90 \\
\hline \multirow[t]{2}{*}{ Wooden roller crusher. } & 25 & 26.7 & 26.5 & 25.4 & 0.51 & 3.82 \\
\hline & 25 & 26.8 & 26.5 & 26.5 & 0.54 & 3.80 \\
\hline \multirow[t]{2}{*}{ Garolla crusher.. } & 50 & 25.4 & 25.1 & 24.5 & 0.52 & 3.80 \\
\hline & 50 & 25.4 & 25.2 & 23.8 & 0.49 & 3.80 \\
\hline
\end{tabular}

Moreover, only 5 clusters were harvested per row. Rows 11 to 20 were sampled as usual (11 and 12 together, etc.).

\section{METHODS OF ANALYSIS}

Since it was believed that the berry and cluster samples from Delano might deteriorate before reaching Davis, they were weighed and crushed at Delano. The juice was then mixed and 250-ml samples were bottled. These were cooled with chopped ice during transportation (about 7 hours). The vine samples were crushed at Davis (with the exception of the first picking of the Carignane lot from Delano, which was crushed at Delano). The samples from all other locations were weighed and crushed as soon as they arrived at Davis and on the same day as harvested.

A laboratory screw-type crusher was used for crushing all lots except the third harvesting of the Carignane vine samples and the fourth harvesting of Semillon vine samples from Davis. These were crushed in the regular Garolla crusher. These two methods of crushing differ, as the data in table 1 indicate.

The Garolla crusher and the wooden crusher obviously crush only the turgid fruit. They give the lowest Balling, sugar, and $\mathrm{pH}$. The screw-type press and the Waring blendor grind up all of the fruit-shriveled, raisined, and turgid. The degree Balling, per cent reducing sugar, and $\mathrm{pH}$ are thus markedly higher. These latter methods of crushing also extract more highly buffered material from the seeds and more of the higher $\mathrm{pH}$ juice of the shriveled fruit, hence the lower titratable acidity and higher $\mathrm{pH}$. Under plant conditions, where all of the crushed grapes ferment together, these 
differences in sugar content are probably less significant since the sugar is more or less completely extracted from the crushed fruit during fermentation, but the Waring blendor and the screw-type press obviously give a better measure of maturity than roller crushers or paddle crushers. The Garolla crusher was used only with vine samples of Carignane and Semillon from the last harvests at Davis; hence it does not, generally, influence the conclusions reached herein.

The analyses were made by the usual procedures followed in this laboratory (Amerine, 1955). The juice was centrifuged before analysis. The Abbé refractometer was operated with tap water flowing through the instrument and with artificial light. Nearly all the Abbé refractometer readings were made by the same person. The hand refractometer was a Zeiss instrument, and the temperature correction was made on the basis of the temperature of the samples, which was not exactly the same as but close to the temperature of the liquid when read in the refractometer.

In cases where the must was fermented, the entire berry sample was placed in a jar of appropriate size, yeasted, and fermented. Cluster samples were also pooled and handled similarly. In the case of the vine samples, the juice was well mixed and then 2 gallons fermented in a 3-gallon jar. In a few cases the small centrifuged samples were also fermented. These did not always ferment out completely, and when they did, the alcohol content was less than in the noncentrifuged samples. Apparently the sugar on the suspended particles of the noncentrifuged samples contributed to the total amount of alcohol.

\section{COMPARISON OF SAMPLING METHODS}

The wine maker is primarily interested in the composition of the musts. There are three aspects to must composition: (1) the differences between the three methods of sampling employed, (2) the differences between the sampling methods and the actual composition of the fruit harvested from the blocks, and (3) the alcohol yield of the fermented wine. This study is primarily concerned with the first point. The results of laboratory sampling and field harvesting, for either must or alcohol yield, are not as close as we should like in most of the blocks for two reasons: field harvest did not always immediately follow the laboratory sampling, and even when it did, the method of determining the composition of the field sample was deficient. The validity of the method of determining field maturity is difficult to prove, since no alcohol yield data are available.

In practice, likewise, the composition of the field samples as reported in the winery is also frequently defective because (a) only small samples are taken from the fruit as it is delivered to the winery, and (b) the method of crushing used by the winery is often of limited accuracy. The winery usually uses roller crushers and these give a lower degree Balling than other, more complete crushing procedures, as indicated in table 1 . All the data reported herein, unless otherwise stated, were obtained from juice from the laboratory model screw-press.

The major results are given in tables 2 to 10. In analyzing these data one 


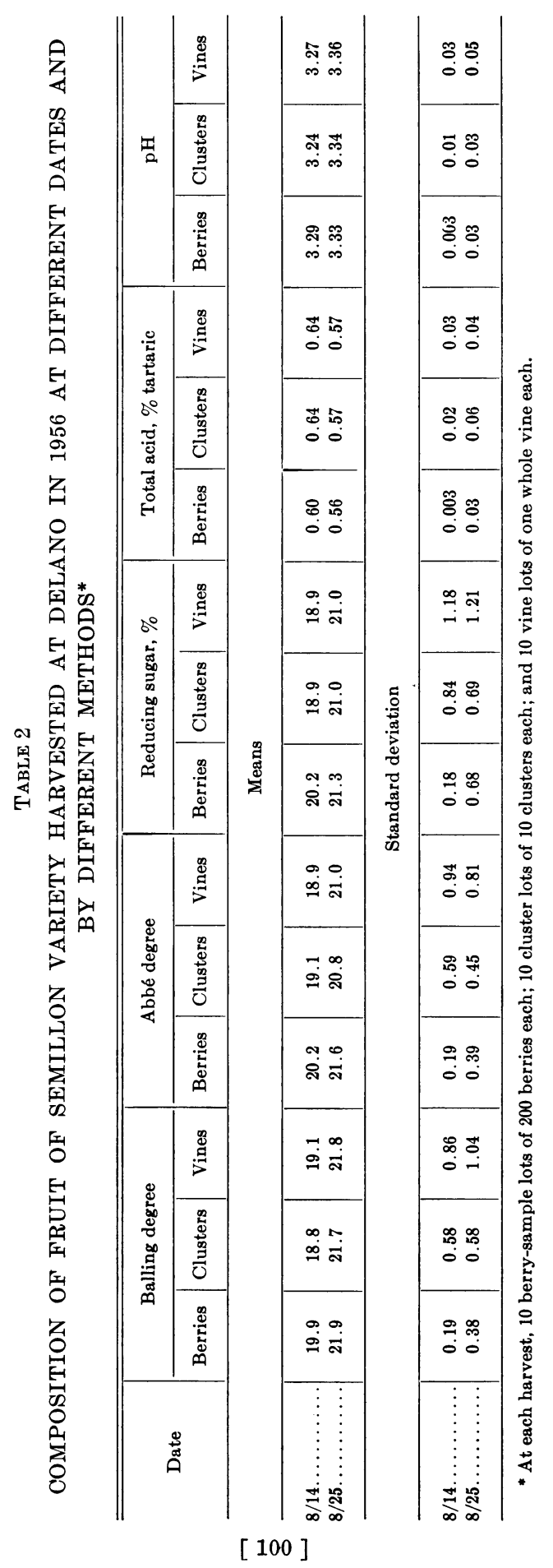




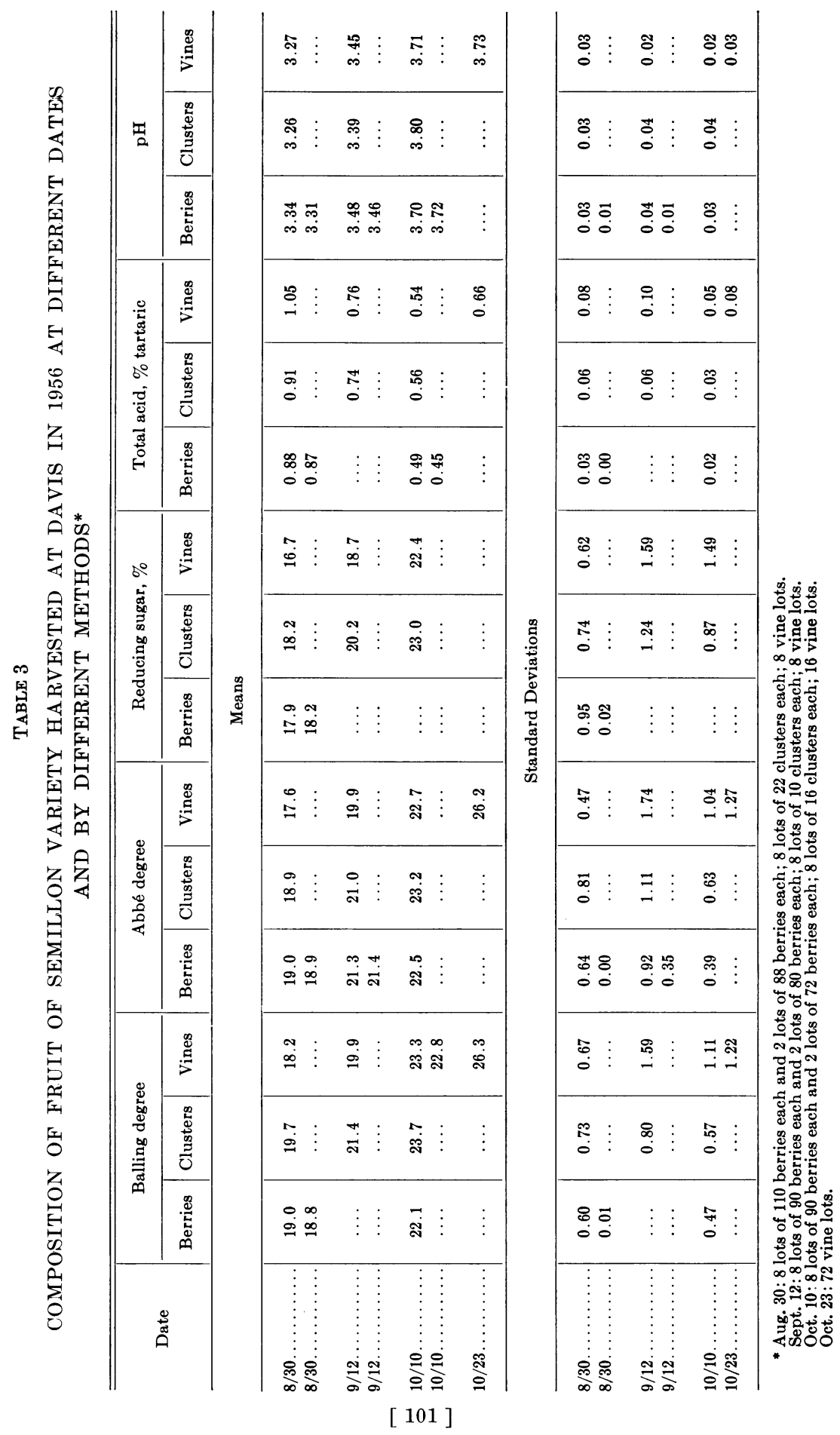




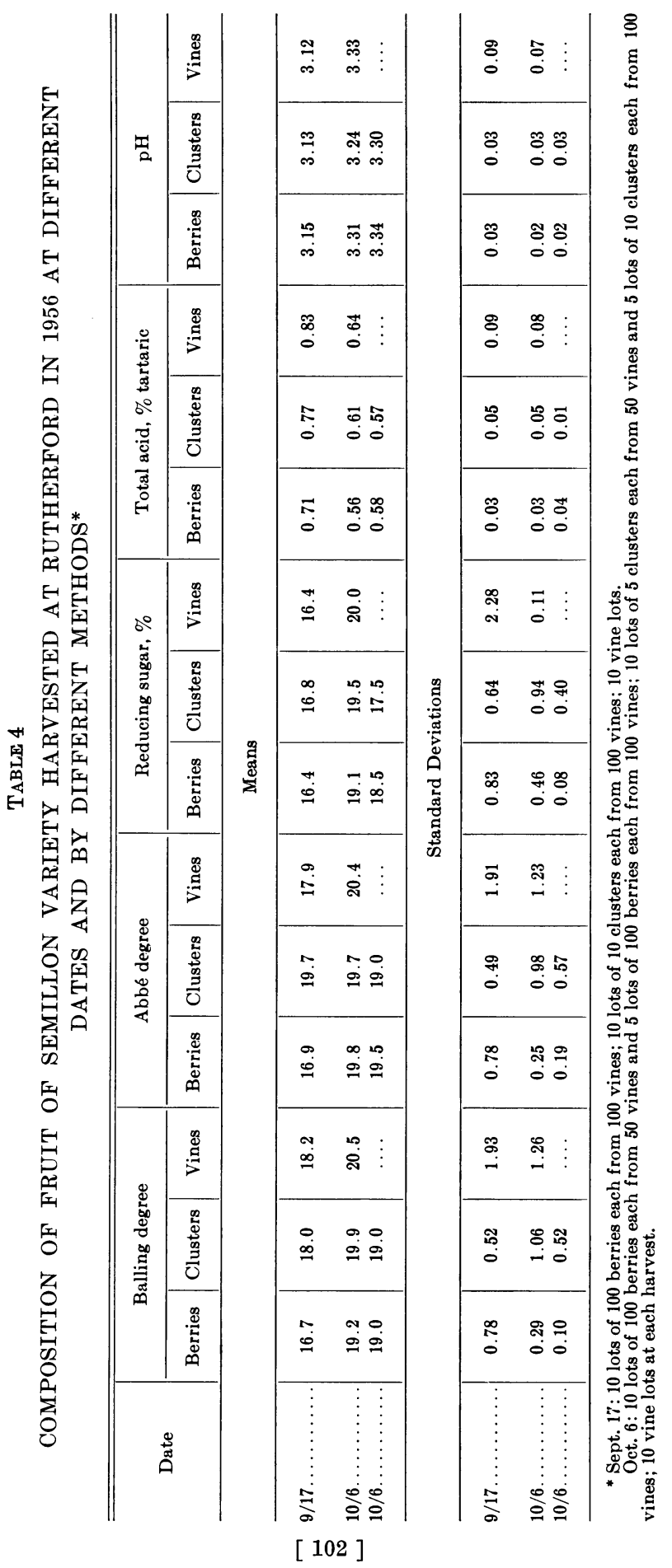




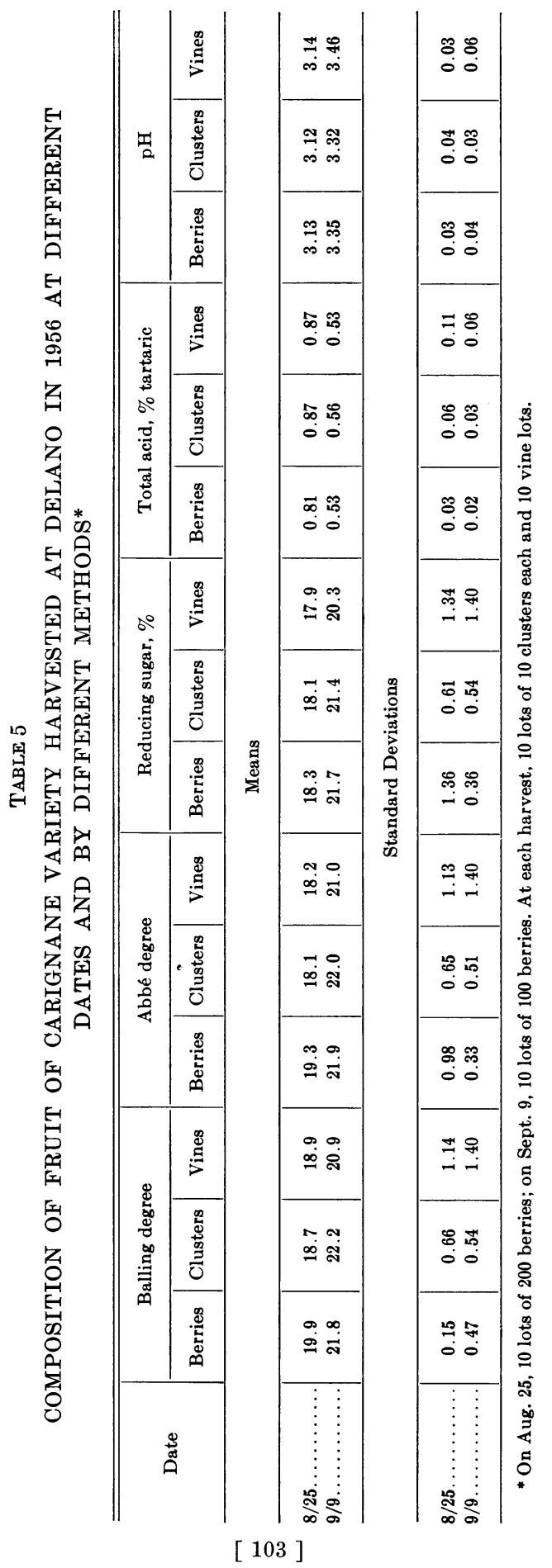




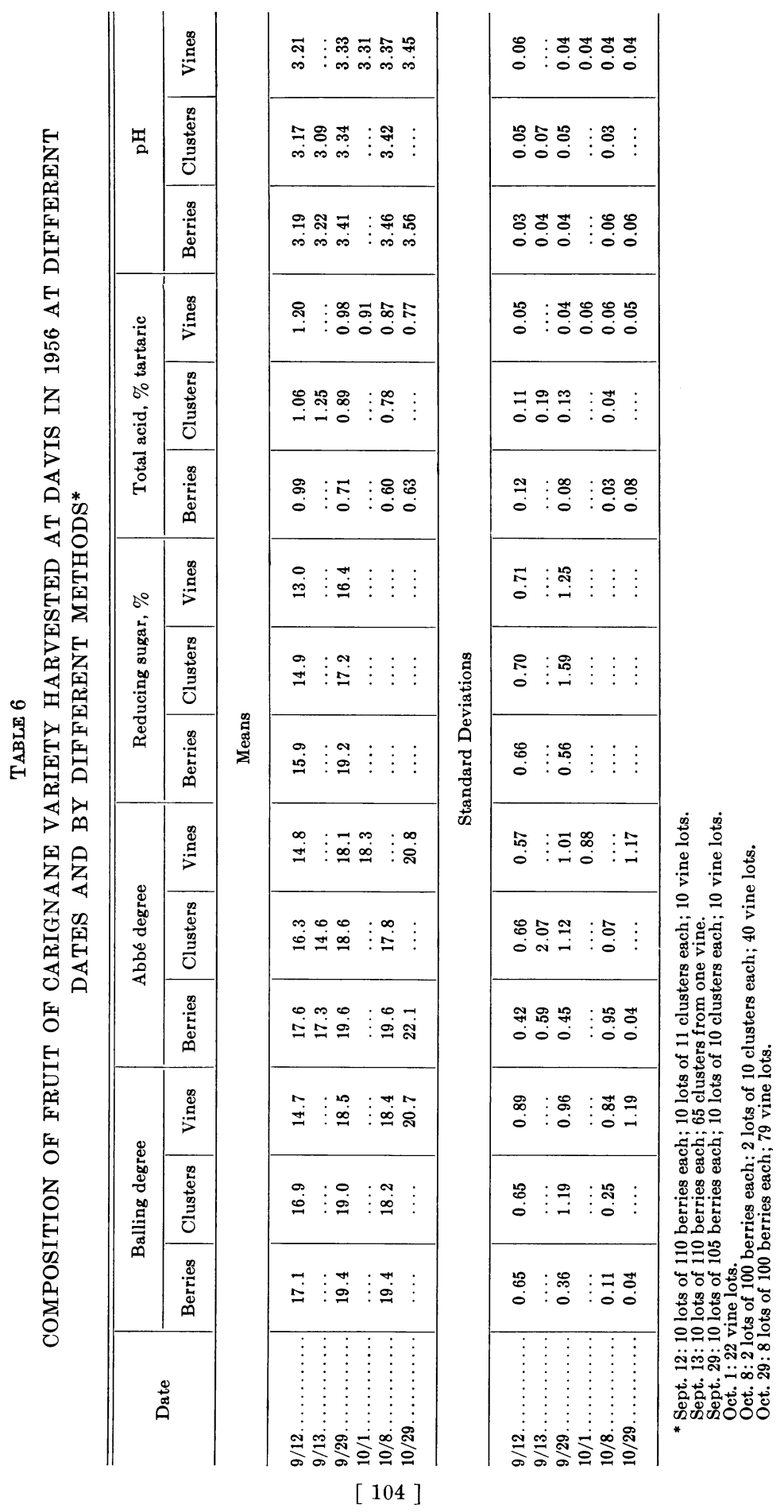




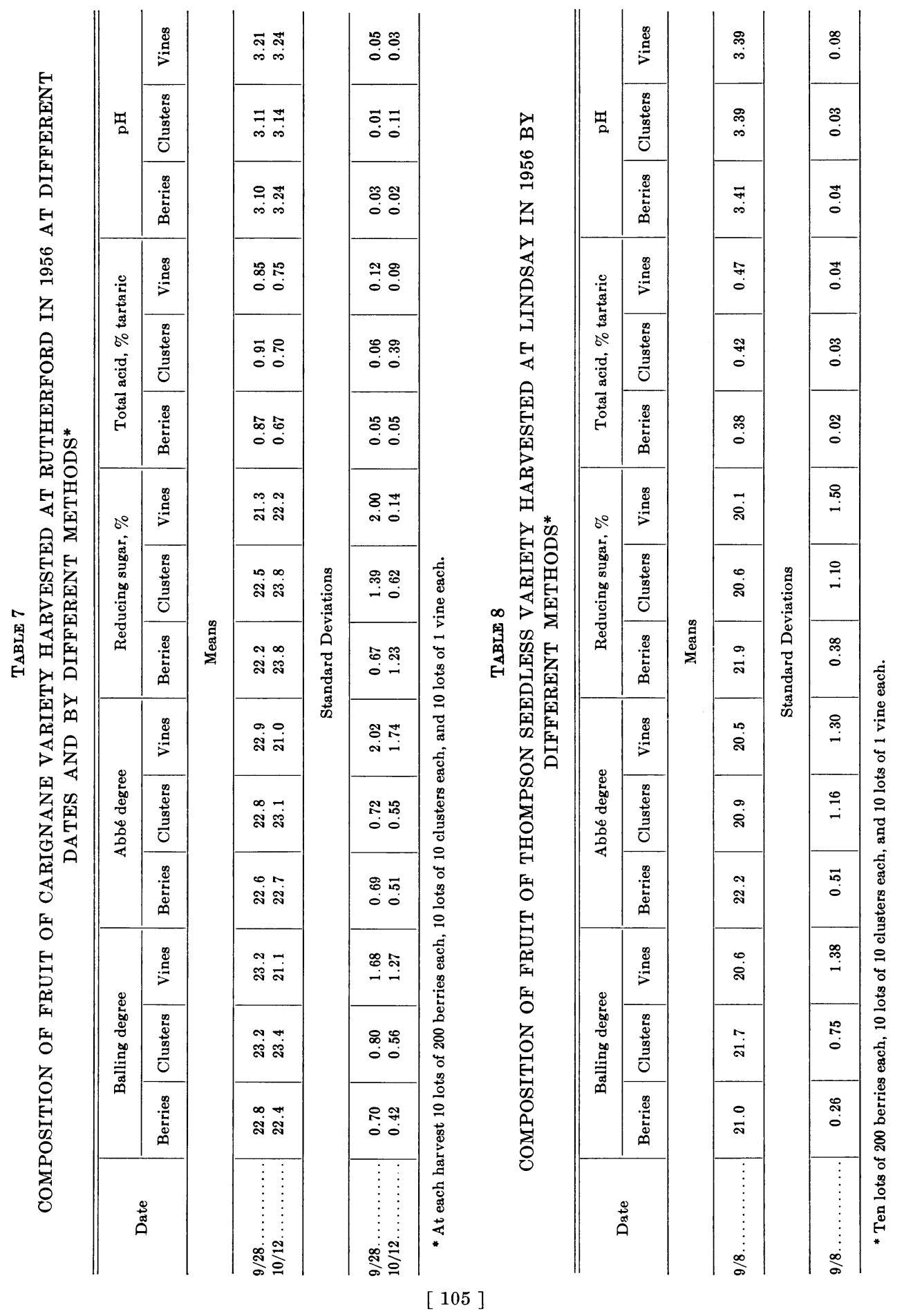




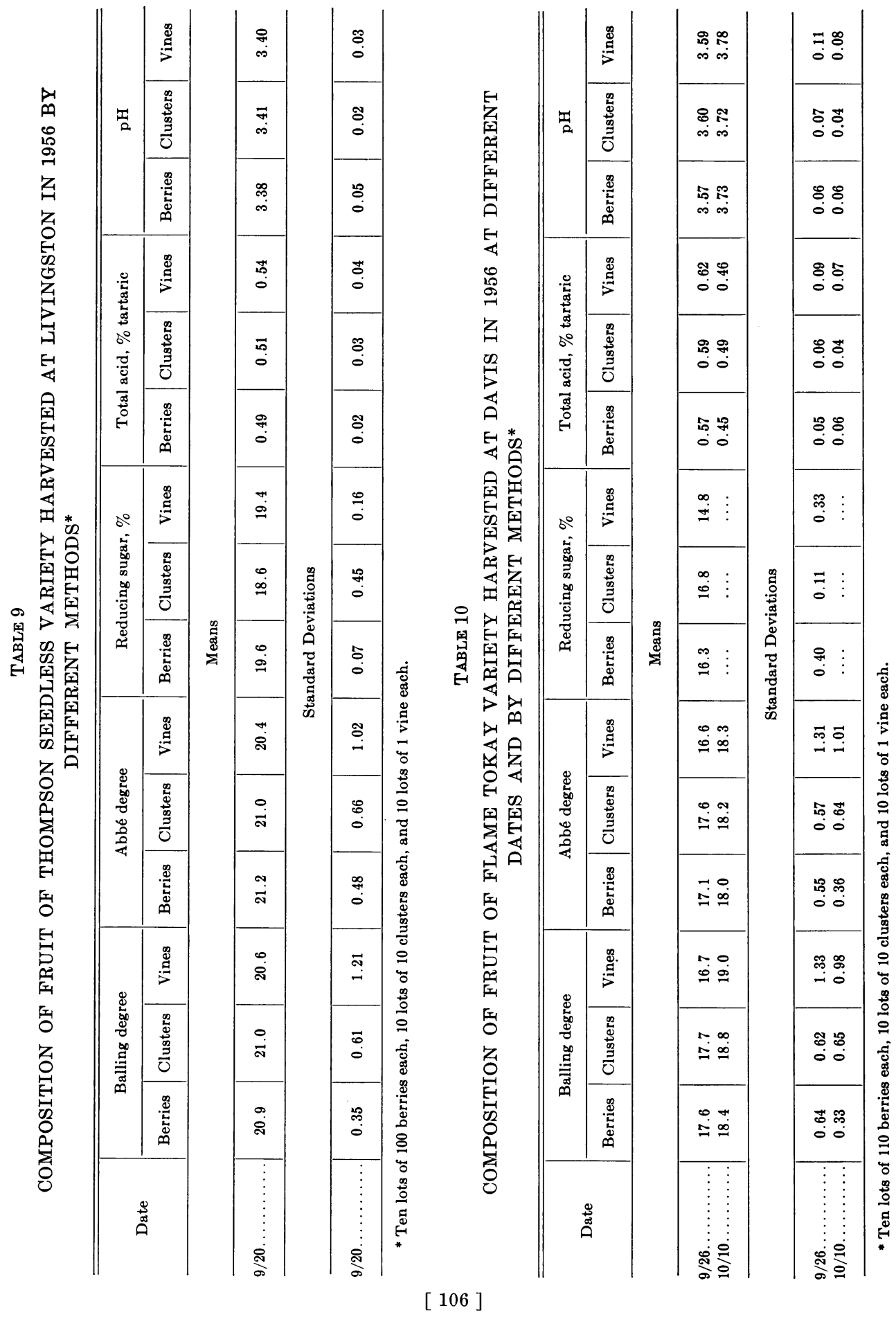


should recall that the standard deviation is a measure of the reliability of the mean. The larger the standard deviation, the less certain we can be that the mean is a close estimate of the population mean (Balling, total acidity, etc.).

Semillon. At Delano (table 2) there was little difference at the first picking between the cluster and vine samplings. The berry samples were slightly more mature-higher Balling and $\mathrm{pH}$ and lower total acidity. However, at the second sampling there was little difference between the three methods of sampling. At these and later samplings with other varieties, the standard deviations of the berry samples are less than for the cluster and vine samples. Statistically this indicates that berry sampling is more uniform, that is, less random, than cluster and vine sampling. Exceptions will be noted as they occur. It is of interest that the larger standard deviations apply to degree Balling (and its related measurements, Abbé refractometer reading and per cent reducing sugar); those for total acidity and $\mathrm{pH}$ are smaller, in some cases considerably so.

At Davis (table 3) the same general conclusions apply. The vine samples are lower in degree Balling, except at the third harvest, than the cluster and berry samples, and their standard deviations, in all cases, are larger. Again, the standard deviations of the total acidity and $\mathrm{pH}$ are very similar for the three methods of sampling. Eight lots of 90 to 110 berries from 9 to 11 vines each gave essentially the same means as two lots of 72 to 88 berries from the same number of vines.

The data for Semillon from Rutherford are given in table 4. At the first picking the berry samples were lower in Balling (and Abbé refractometer reading and reducing sugar) than the cluster and vine samples. At the second harvest there was little difference between the three, but the vine samples were again slightly riper. The standard deviations were generally smaller for the berry samples than for the cluster and vine samples. It is somewhat anomalous that the one-berry-per-vine samples had a smaller standard deviation than the two-berry-per-vine samples. The five-cluster samples had, however, a lower standard deviation than the 10-cluster samples, as expected. Again, the standard deviations of the vine samples were less than those of the other two sampling methods, but the differences were small.

Carignane. At Delano (table 5) there was little difference in the two harvests between the three methods of sampling. Again for the degree Balling (and Abbé refractometer reading, per cent reducing sugar, and per cent alcohol) the standard deviation was generally less for berry sampling than for the cluster and vine sampling. The means and standard deviations for per cent total acidity and $\mathrm{pH}$ differed little between the three procedures.

The Davis samples (table 6) were lower in Balling (and Abbé refractometer reading and per cent reducing sugar) for the vine samples than for the berry or cluster samples at the first harvesting. Thereafter there was little difference between the three. Moreover, the standard deviations of the three sampling procedures did not differ in such a uniform fashion as in the previous examples. In general, however, the standard deviations of the vine samplings were greater than those of the other two procedures. 
For the October 8th harvest only two lots of 100 berries and two lots of 10 clusters were compared with 40 vine samples. The comparisons were still rather close.

On October 29th, 100 berries were harvested from each of four rows by two pickers. The following means were noted:

\begin{tabular}{|c|c|c|c|c|c|}
\hline & $\begin{array}{l}\text { Weight } \\
\text { per berry } \\
\text { gm }\end{array}$ & $\begin{array}{c}\text { Abbé } \\
\text { degrees }\end{array}$ & $\begin{array}{c}\text { Zeiss } \\
\%\end{array}$ & $\begin{array}{c}\text { Total } \\
\text { acidity } \\
\% \text { tartaric }\end{array}$ & $\mathrm{pH}$ \\
\hline $10 \mathrm{~K}$ & 2.39 & 22.1 & 21.8 & 0.62 & 3.58 \\
\hline Picker 2 & 2.39 & 22.2 & 21.8 & 0.65 & 3.53 \\
\hline
\end{tabular}

Other comparisons between pickers showed small but rather inconsistent differences, indicating that this is a minor variable which, nevertheless, should be controlled. At the same time 20 vines each from four rows were harvested. The Abbé reading is lower for the vine samples, the total acidity is higher, and the $\mathrm{pH}$ lower, indicating that at this late harvest date the pickers had a tendency to pick riper berry samples. It should be noted that the vines were heavily cropped (over $40 \mathrm{lbs}$. average per vine) and some vines had "red" berries. There is a psychological difficulty in getting pickers to harvest abnormal berries. This illustrates that sampling problems are likely to be more difficult when the fruit is very variable in maturity. The Ballings of the 80 vines varied from $18.6^{\circ}$ to $23.4^{\circ}$.

At Rutherford (table 7) the results were quite anomalous. The Balling readings (Abbé refractometer reading and per cent reducing sugar) at the second harvest differed little from or were lower than those of the first harvest. The origin of this reversal is not readily apparent. Obviously some undetected sampling error was operative. However, in common with most of the earlier results, the standard deviations of the vine samples were greater than those of the berry or cluster samples.

Thompson Seedless. The samples from Lindsay (table 8) show that the berry and cluster samples were higher in degree Balling (and Abbé refractomer reading, per cent reducing sugar, and per cent alcohol) than the vine samples. The standard deviations of the former were, however, uniformly lower. The per cent total acidity and the $\mathrm{pH}$ values also generally indicate that the berry samples were riper. Their standard deviations, though lower, were very similar to those of the vine samples.

At Livingston (table 9) the results were not so clear. In degree Balling (and Abbé refractometer reading and per cent reducing sugar) the berry samples differed little from the vine samples, and readings were lower than for the cluster samples. However, the standard deviations for vine samples were again higher than for the other two methods of sampling. Furthermore, the per cent total acidity indicated that the vine samples were less ripe. The standard deviations for total acidity differed little between the three procedures.

Flame Tokay. At the first harvest (table 10) the degree Balling (and Abbé refractometer reading and per cent reducing sugar) was greater in the cluster samples. The second harvest showed slightly higher Balling readings for the cluster and vine samples. The standard deviations for the vine 


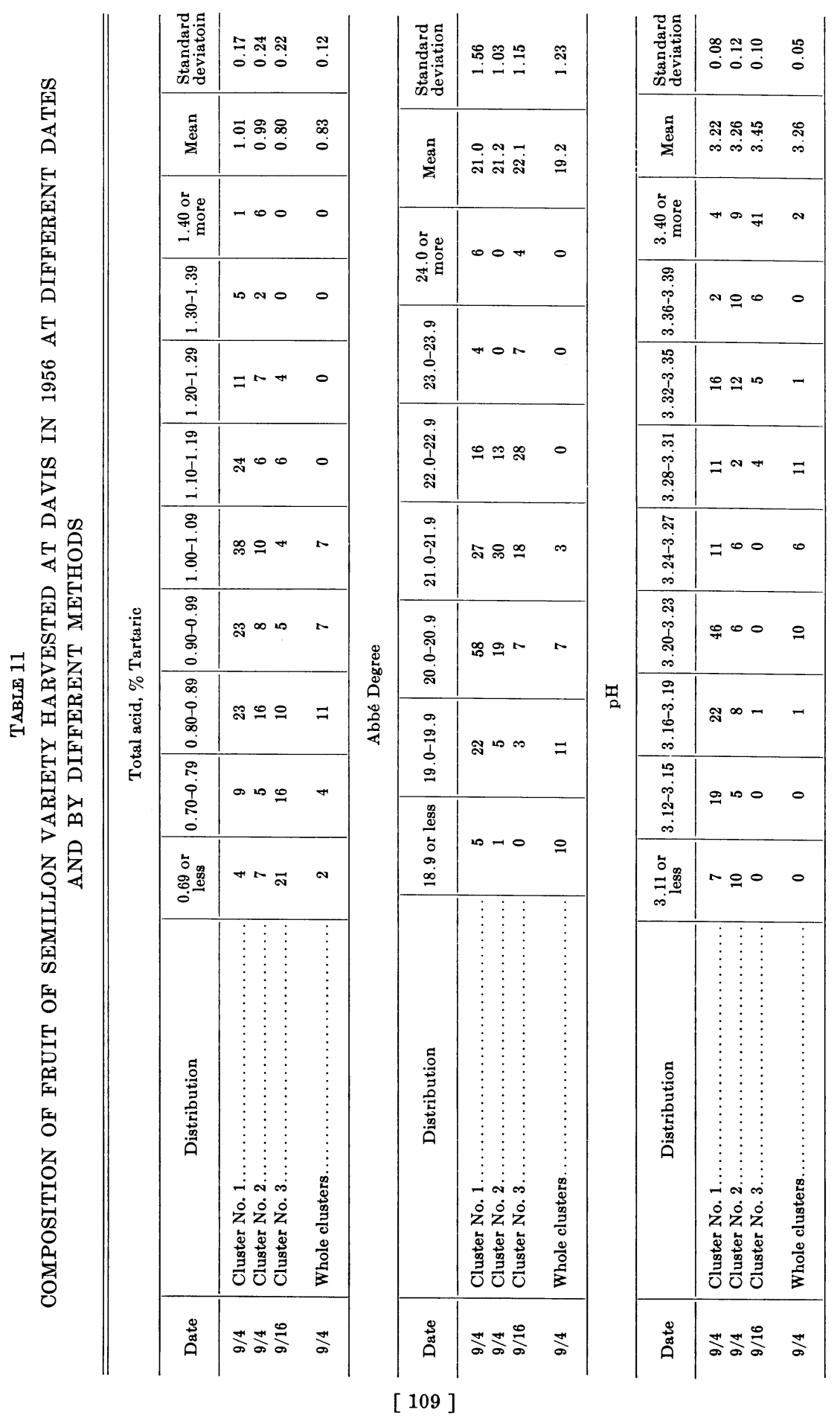


samples were larger for both samplings. There was little difference, as previously, for the standard deviations of the total acidity and $\mathrm{pH}$ among the three methods of sampling for the two harvests.

For the four varieties sampled from the three climatic regions (I, IV, and V), berry, cluster, and vine sampling generally gave about the same degree Ballings (and Abbé refractometer readings, per cent reducing sugar, and per cent alcohol) for the four varieties sampled-Semillon, Carignane, Thompson Seedless, and Flame Tokay. However, the standard deviations of the means of the vine samples were greater. The total acidity and $\mathrm{pH}$ values indicate that the berry samples were slightly more mature than the cluster and vine samples. On the other hand, the means of the vine samplings are less reliable because of their higher standard deviations which indicate their greater variability. Although the data were subjected to statistical treatment, the variability is such that no consistent pattern of significance is apparent, hence no more detailed statistical treatment is justified.

From the data we conclude that for varieties of normal maturity, berry sampling offers a simpler and more rapid method of field sampling for grape maturity. If substantiated by further studies and for other varieties, berry sampling should be seriously considered by both growers and experimenters as the preferred method for measuring field maturity.

\section{SOURCES OF VARIABILITY}

After these experiments were started it became obvious that it would be desirable to isolate the source of the great variability in field samples. Three sampling procedures were used to make the following comparisons: differences in berries on a single cluster, differences between clusters, and differences between vines.

Actually, the three sampling procedures provided some measure of variability. The standard deviations of berry samples were generally less than those of cluster samples, and vine samples had the largest standard deviations.

In table 11 the results of sampling individual berries from single clusters of Semillon grapes at Davis on September 14 and 16 are summarized. Single whole clusters of Semillon from Davis were also analyzed on September 4, and the results are also given in table 11 . The distributions are generally not normal. The reasons for this are not readily apparent and will be further investigated.

\section{CHANGES DURING THE SEASON}

La Rosa and Nielsen (1956) have presented data indicating that in their 1954 studies loss in weight occurred in grapes without simultaneous increase in Balling. Their 1955 data showed some decreases in weight, but in this case they were offset by proportionate increases in Balling.

The data in table 12 do not substantiate those obtained by La Rosa and Nielsen. Either the weight and Balling increase throughout the season, or if the weight decreases, as for the Semillon at Delano, the Balling continues to increase. The problem then arises of how to account for the 1954 data of 
La Rosa and Nielsen. The most obvious answer is that their method of crushing resulted in less extraction of sugar from overripe grapes than from unripe grapes. They used a roller crusher and, as shown in table 1, less sugar is extracted by the roller crushers. This would be particularly true late in the season, and the effect would be greater in a warm than in a cool season.

TABLE 12

CHANGES IN BALLING, WEIGHT PER VINE, CLUSTER AND BERRY DURING MATURATION

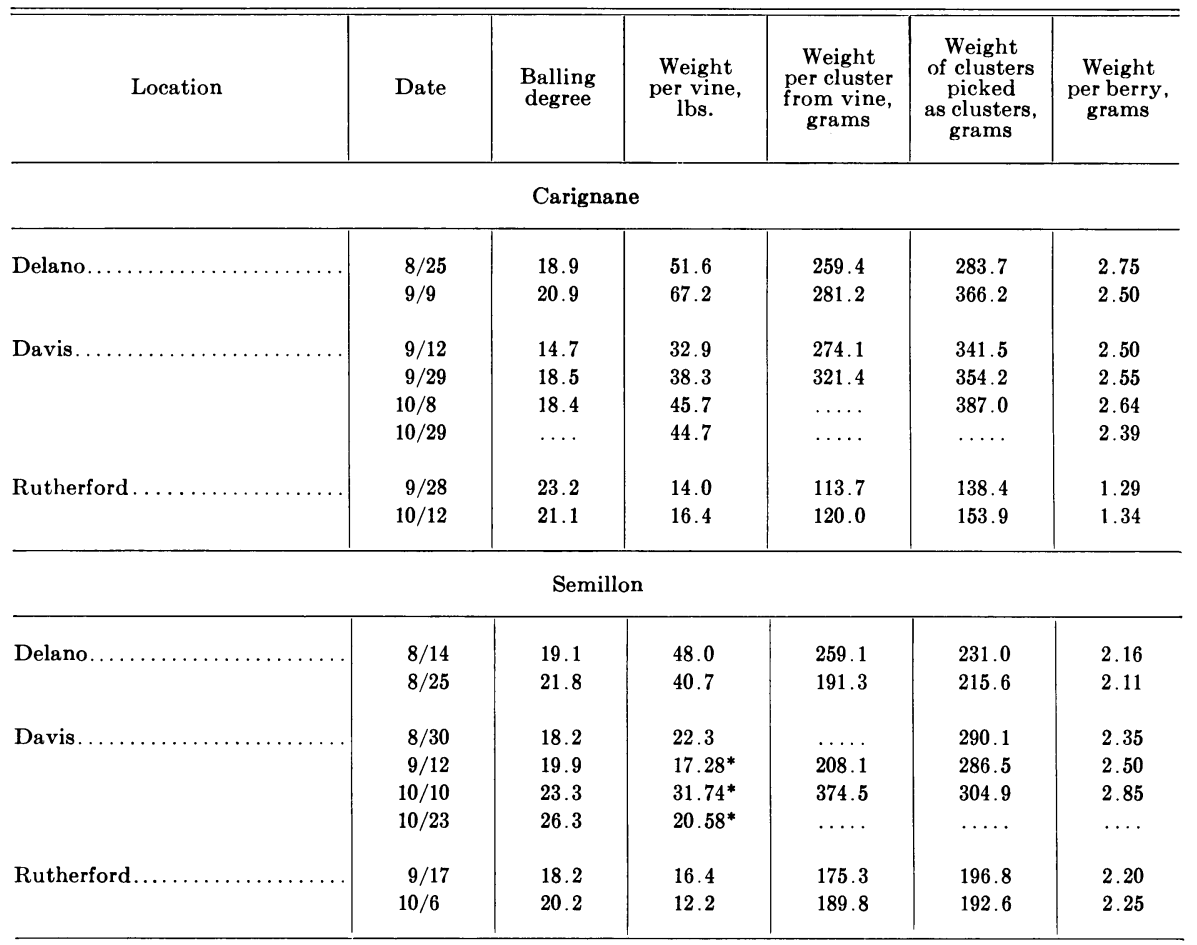

* Weight of clusters removed at earlier harvesting taken into account.

\section{YIELD DATA}

The grower is more interested in the yield per acre, though he too, if paid on some Balling-weight basis, is concerned with the composition of the fruit. The data in table 13 indicate that the sampling methods used may underor overestimate the potential maturity. This is easy to understand since the cluster samples are more likely to be taken from the larger, more obvious clusters. The data in table 13, taken from all the tests, further substantiate this.

\section{SUMMARY}

1. Three different methods of field sampling-berry, cluster, and vinewere compared. Semillon and Carignane grapes from regions II, IV, and V, 


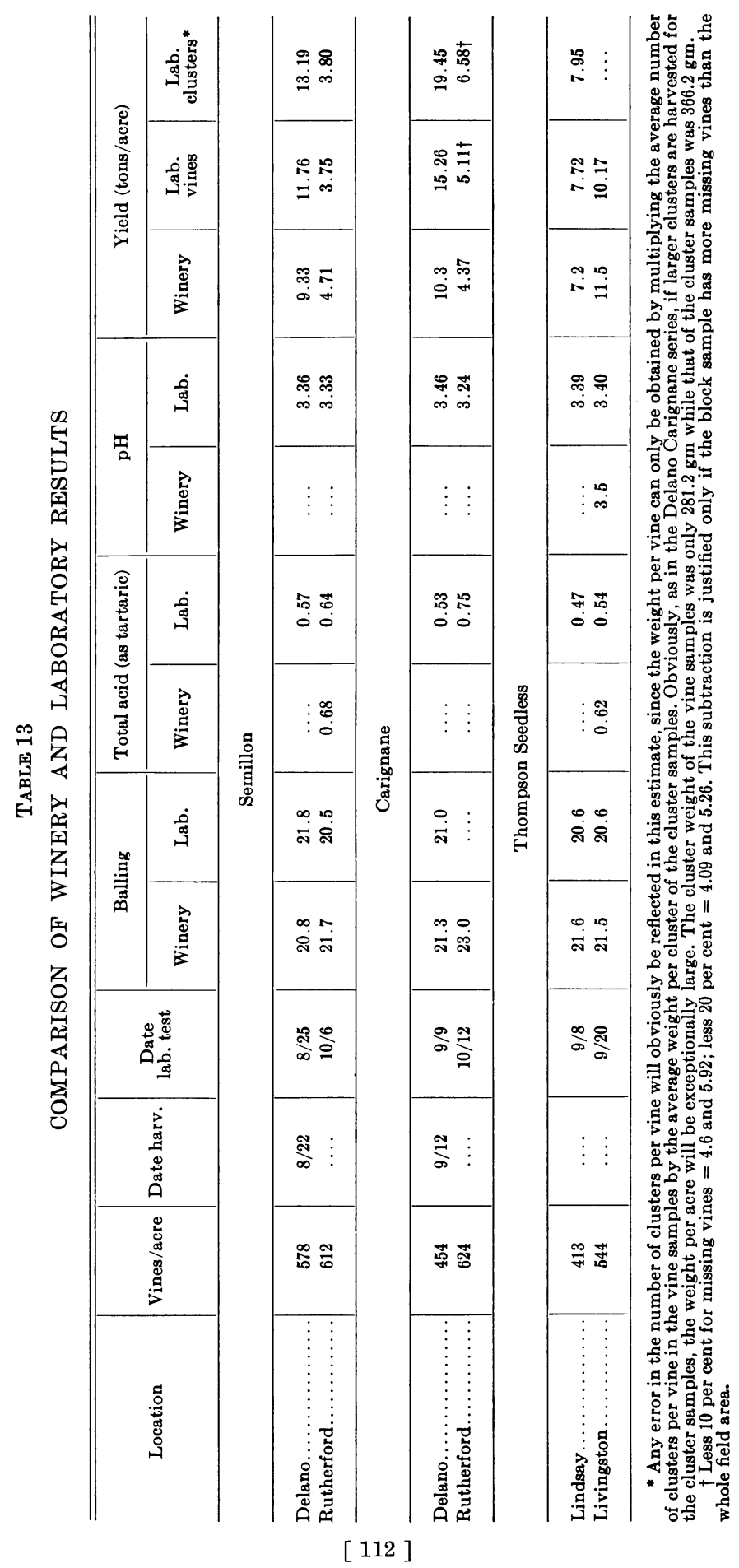


Thompson Seedless from regions IV and V, and Flame Tokay from region IV were sampled. One to four collections were made during the season.

2. A laboratory screw-type press was used for crushing. It was shown that wooden roller crushers or a Garolla crusher gave musts with $1^{\circ}$ to $2^{\circ}$ less Balling than the screw press. The degree Balling, Abbé refractometer reading, per cent reducing sugar, per cent total acidity, and $\mathrm{pH}$ were determined on all samples. In some cases Zeiss hand refractometer readings were also obtained, and the juice was fermented and the alcohol content determined.

3. Berry, cluster, and vine sampling gave similar maturity values. There was a tendency for the berry or cluster samples to be riper, particularly early in the season, but this was offset by the greater variability of the vine samples, as reflected in the higher standard deviations. Furthermore, where alcohol determinations were made, the three methods compared very favorably.

4. The source of the variability was studied by analyzing individual berries and clusters. Since the frequency distributions were non-normal, further study is necessary.

5. No evidence of weight losses during ripening without increase in sugar was obtained.

6. Actual yields were less than the estimates made from cluster and vine samples.

\section{ACKNOWLEDGMENTS}

We are indebted to Mr. Gordon Madley, Mr. Donald Neutermann, Mr. Cornelius Ough, and Mr. George Thoukis for assistance in harvesting the fruit and in conducting the analyses, and to Mrs. Frances Jones for statistical analysis of the data. We also acknowledge the advice of Mr. Harold Berg, Professor G. A. Baker, and Professor A. J. Winkler, who read the manuscript.

\section{LITERATURE CITED}

Amerine, M. A.

1955. Laboratory procedures for enology. Department of Viticulture and Enology. University of California, Davis. 108 p. (mimeo.)

1956. The maturation of wine grapes. Wines and Vines $37: 27-30,32,34-36,53-55$.

Andre, Charles, Lemineur, Michel, ORIzet, Rivorre, Vedei

1951. Contribution à l'étude de la maturation du raisin. Prog. Agr. et Vitic. 136:99$103,114-128,141-152$.

Benvegnin, L., and E. CAPT

1955. L'échantillonnage à la vigne pour l'évaluation de la maturité du raisin sur cep. Rev. Romande d'Agric., de Vitic. et d'Arbor. 11:13-14.

BERG, H. W., and G. L. MARSH

1954. Sampling deliveries of grapes on a representative basis. Food Tech. 8:104-108. Fisher, R. A.

1950. Statistical methods for research workers. 11th ed. New York, Hafner Co. 354 p. FLANZT, M.

1955. Charactéristiques des raisin. Raisins à vins, raisins de table et raisins à jus de fruits. Ann. Nutrition et Aliment. 9:A113-A141. 
HugLin, P.

1955. Étude sur la morphologie, la phénologie et la productivité des principaux cépages de $V$. vinifera L. cultivés an Alsace. Annales Amélior. Plantes 5:5-51.

JАСOB, H. E.

1942. Relation of the maturity of the grapes to the yield, composition and quality of raisins. Hilgardia $14: 321-345$.

LA Rosa, W. V., and U. NIELSEN

1956. Effect of delay in harvesting on the composition of grapes. Amer. Jour. Enol. $7: 105-111$.

WINKLER, A. J.

1932. Maturity tests for table grapes. California Agr. Exp. Sta. Bull. 529. 35 p. 
The journal Hilgardia is published at irregular intervals in volumes of about 600 pages. The number of issues per volume varies.

Subscriptions are not sold. The periodical is sent as published only to libraries, or to institutions in foreign countries having publications to offer in exchange.

You may obtain a single copy of any issue free, as long as the supply lasts; please request by volume and issue number from:

Agricultural Publications

Room 22, Giannini Hall

University of California

Berkeley 4, California

The limit to nonresidents of California is 10 separate issues on a single order. A list of the issues still available will be sent on request. 